
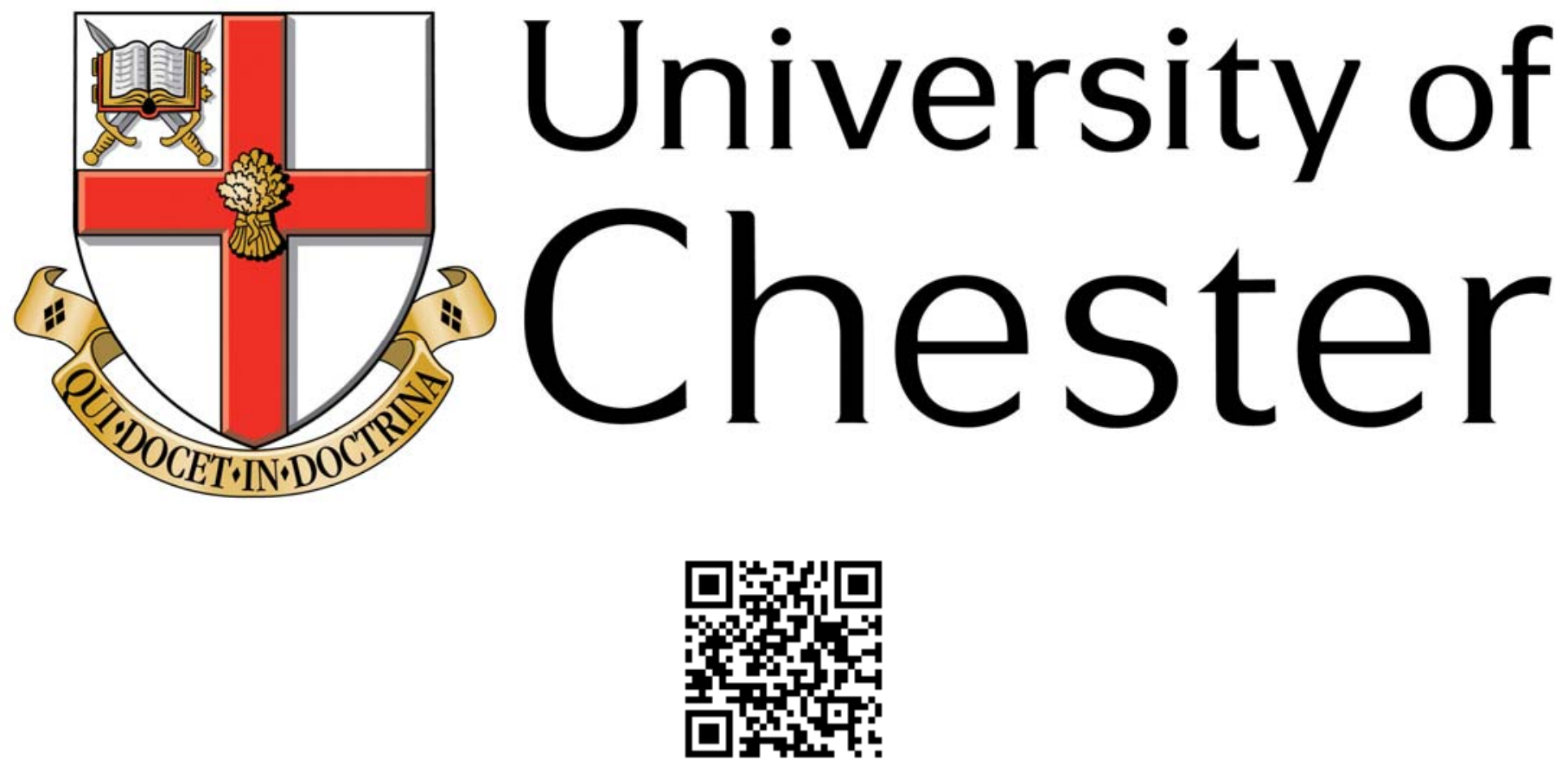

This work has been submitted to ChesterRep - the University of Chester's online research repository

\title{
http://chesterrep.openrepository.com
}

Author(s): Mark Waldron; Paul R Worsfold; Craig Twist; Kevin Lamb

Title: A three-season comparison of match performances among selected and unselected elite youth rugby league players

Date: 2014

Originally published in: Journal of Sports Sciences

Example citation: Waldron, M., Worsfold, P.R., Twist, C., \& Lamb, K. (2014). A three-season comparison of match performances among selected and unselected elite youth rugby league players. Journal of Sports Sciences, 32(12), 1110-1119

Version of item: Authors' post-print (author accepted manuscript)

Available at: http://hdl.handle.net/10034/314705 


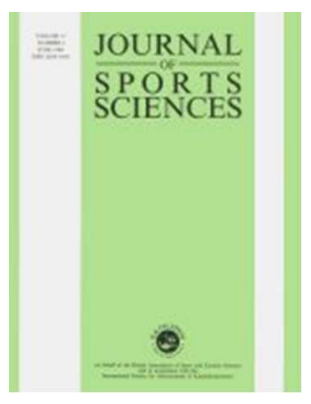

\section{A three-season comparison of match performances among selected and unselected elite youth rugby league players}

\begin{tabular}{|r|l|}
\hline Journal: & Journal of Sports Sciences \\
\hline Manuscript ID: & RJSP-2013-0295.R3 \\
\hline Manuscript Type: & Original Manuscript \\
\hline Keywords: & Global Positioning Systems, talent, team sport \\
\hline \multicolumn{3}{|c}{} \\
\multicolumn{3}{c}{$\begin{array}{c}\text { SCHOLARONE } \\
\text { ManusCripts }\end{array}$} \\
\end{tabular}

URL: http://mc.manuscriptcentral.com/rjsp 
1

2

3

4

5

6

7

8

9

10

11

12

13

14

15

16

17

18

19

20

21

22

23

24

25

26

27

28

29

30

31

32

33

34

35

36

37

38

39

40

41

42

43

44

45

46

47

48

49

50

51

52

53

54

55

56

57

58

59

60

Title: A three-season comparison of match performances among selected and unselected elite youth rugby league players

Running title: Youth rugby league match performance

Key Words: Global Positioning Systems; talent; team sport 


\begin{abstract}
This study compared technical actions, movements, heart rates and perceptual responses of selected and unselected youth rugby league players during matches (under-15 to under-17). The players' movements and heart rates were assessed using $5 \mathrm{~Hz}$ Global Positioning Systems (GPS), while their technical actions were analysed using video analysis. The maturity of each player was predicted before each season for statistical control. There were no differences $(P>0.05)$ between selected and unselected players in the under-15 or the under-17 age groups for any variables. However, in the under-16 group, the selected players $(57.1 \pm 11.9 \mathrm{~min})$ played for longer than the unselected players $(44.1 \pm 12.3 \mathrm{~min} ; P=0.017$; $\mathrm{ES}=1.08 \pm \mathrm{CI}=0.87)$, and covered more distance $(5,181.0 \pm 1063.5 \mathrm{~m} c f .3942 .6 \pm 1,108.6$ $\mathrm{m}$, respectively; $P=0.012 ; \mathrm{ES}=1.14 \pm \mathrm{CI}=0.88)$ and high intensity distance $(1,808.8 \pm$ $369.3 \mathrm{~m} c f .1,380.5 \pm 367.7 \mathrm{~m}$, respectively; $P=0.011 ; \mathrm{ES}=1.16 \pm \mathrm{CI}=0.88)$. Although successful carries per minute was higher in the selected under-15 group, there were no other differences $(P>0.05)$ in match performance relative to playing minutes between groups. Controlling for maturity, the less mature, unselected players from the under-16 group performed more high-intensity running $(P<0.05)$. Our findings question the use of matchrelated measurements in differentiating between selected and unselected players, showing that later maturing players were unselected, even when performing greater high-intensity running during matches.
\end{abstract}




\section{Introduction}

The requirements of competitive match play have been well documented in adult rugby league players (McLellan, Lovell \& Gass, 2011; Waldron, Twist, Highton, Daniels \& Worsfold, 2011a; Sykes, Twist, Hall, Nicholas \& Lamb, 2009). For example, Super League players that complete a full match cover approximately 7,000 $\mathrm{m}\left(\sim 90 \mathrm{~m} \cdot \mathrm{min}^{-1}\right)$, including 1,000 $\mathrm{m}\left(\sim 15 \mathrm{~m} \cdot \mathrm{min}^{-1}\right)$ at high $\left(>14 \mathrm{~km} \cdot \mathrm{h}^{-1}\right)$ running speeds (Waldron et al., 2011a). Importantly, mean heart rates of approximately $80 \%$ of peak values (Waldron et al., 2011a; Coutts, Reaburn \& Abt, 2003) suggest that the movement patterns observed during matches place high demand on aerobic energy pathways. In addition, senior rugby league players have been shown to be involved in $\sim 0.3-1.0$ collisions and carry the ball $\sim 0.2$ per minute of match time (Gabbett, Jenkins \& Abernethy, 2012). Conversely, little is understood regarding the movement demands and match-related skills of youth rugby league players. As such, youth rugby league practitioners have limited objective data on which to base their training practices, and indeed, their initial identification of young, talented players

Typically, youth rugby league players have been assessed for their physical abilities, such as speed, agility and strength (Till et al., 2011; Gabbett, 2009). The limitations of such tests have been previously highlighted, with no differences in speed, agility, aerobic endurance power or vertical jump height identified within regional or national level under-15 players (Till et al., 2011). Adopting a similar selection of tests, under-18 Australian players, who were either selected or unselected to play in competitive matches, also demonstrated no differences in their physical abilities (Gabbett, 2009). Given that talent in sport may be defined as "someone who performs better than his or her peers during competition and who has the potential to reach the elite level" (Elferink-Gemser, Visscher, Lemmink \& Mulder, 
2004, p. 1,053), the assessment of match-related performance might extend the current understanding of what characterizes talented rugby league players. Whilst the limitations of identifying higher ability from performance measurements taken in a field or laboratory (closed) environment have been expressed (Vaeyens, Güllich, Warr \& Philippaerts, 2009; Falk, Lidor, Langer \& Lang, 2004), no research to date has measured performance from the match environment for such purposes.

The adoption of such measures appropriately addresses to the inherent limitations of talent identification research that has relied upon tests of 'closed' ability (Waldron \& Worsfold, 2010). It has been recently suggested that researchers should use measurement techniques that reflect the performance of players form within an 'open' environment (Unnithan, White, Georgiou, Iga \& Drust, 2012), thus assessing the ability of players to interact with a rapidly changing environment, rather than the proficiency of a 'learned technique' (Ali, 2011). Moreover, talent identification research among youth rugby league players is typically undertaken using cross-sectional, rather than longitudinal, study designs. Undertaking longitudinal research helps to identify the consistency of performance qualities that might distinguish between coach-selected or unselected players across successive age groups. Accordingly, the aims of this study were to compare the technical actions, movements, heart rates and perceptual responses of selected and unselected youth rugby league players during matches across a period of three seasons (under-15 to under-17).

\section{Methods}

\section{Participants and design}


The participants (Table 1) were all players from the same professional Super League club and were assessed throughout each season of the study (under-15, -16, and -17). At the end of each season, six club coaches either selected or unselected players based on their subjective selection criteria (of which there were no formal guidelines). The selected players went on to play the following season, whereas the unselected players were released from the club. Throughout the study period, the same coaches were responsible for the selection of players. At each age group, new players were introduced to the cohort, which yielded the sample sizes described in Table 1. For example, there were 16 selected players at the end of the under-15 age group, who were joined by an additional five players for the start of the under-16 age group $(n=21)$. At the end of the under-16 age group, only 13 of these players were selected by the coaches, and eight were unselected. The Faculty of Applied Health Sciences' Research Ethics Committee gave ethical approval for the study and informed consent was obtained from the participants, parent/guardians, and the Rugby Football League. Whilst the final age group under analysis is referred to herein as the under-17 group, players were contracted to the club as under-18 Academy players, resulting in an amalgamation with players one year older. All of the players typically took part in two to three training sessions per week, consisting of field-based aerobic training, gym-based resistance training, and small-sided rugby games.

************************Table 1 near here $* * * * * * * * * * * * * * * * * * * * *$

During the spring/summer competition period (beginning of March to the end of June), a total of 72 (distributed across six matches), 60 (distributed across six matches) and 68 (distributed 
across seven matches) performances were analyzed in the under-15, under-16 and under-17 group, respectively. Mean match times were $64.1 \pm 2.3$ minutes (under-15 group), $74.5 \pm 3.3$ minutes (under-16 group) and $85.2 \pm 4.1$ minutes (under-17 group). Of the 19 matches analyzed, 17 were won and two were lost, with an average point deficit of $(40.4 \pm 30.6)$. Measures of technical skills, heart rates, perceptual responses and movement demands were assessed for each player during each performance (minimum of two and maximum of five performances per player). Players were analyzed only during the time spent performing, which was different for all players. In rugby league, teams are permitted to interchange players at any given time point, often resulting in players from the forward group performing two separate bouts of play. An interchange allowance of 10 was permitted in the under-15 and -16 age groups, which was decreased to eight in the under-17 age group owing to changes in the rules of the game.

\section{Movement analysis}

Movement analysis was performed using portable GPS devices (SPI-Pro; $5 \mathrm{~Hz}$, GPSports, Canberra, Australia) integrated with an in-built $6 g$ tri-axial accelerometer $(100 \mathrm{~Hz})$. For all matches throughout the testing period a mean \pm SD of $9 \pm 1$ (range between $6-12$ ) satellites were determined as available for signal transmission using Team AMS V2.1 software (GPSports, Canberra, Australia). This has been previously reported as acceptable for assessing human movement (Jennings et al., 2010). The mean horizontal dilution of precision was $1.58 \pm 0.43$ and ranged from 0.87 to 2.01 for all recorded matches. A horizontal dilution of precision of 1 indicates an optimal geometrical positioning of orbiting satellites for accurate monitoring of position, which can reach a score of 50 , in the least reliable case (Jennings, Cormack, Coutts, Boyd \& Aughey, 2010; Witte \& Wilson, 2005). The mean 
temperature during all matches was $9.3 \pm 3.6{ }^{\circ} \mathrm{C}$. All GPS units (maximum of sixteen per match) were simultaneously activated at pitch side, approximately 15 min prior to the 'warmup' period. The players were pre-fitted with an appropriately sized vest housing the portable GPS unit between the scapulae. A standard squad shirt was worn over the top of the vest. The GPS device (mass of $86 \mathrm{~g}, 0.8 \times 0.4 \times 0.2 \mathrm{~cm}$ ) was fitted to the vest of the player upon entering the field for the warm-up. A digital watch was synchronized with Greenwich Mean Time and used to record the start and end of each half. These times were later used to truncate the raw GPS data file. In addition, the time of interchanged players was recorded live and used to further truncate raw data. All data were downloaded to a computer using SPI Ezy V2.1 (GPSports, Canberra, Australia) and analyzed using Team AMS V2.1 software (GPSports, Canberra, Australia).

Twenty-one different movement variables were considered for analysis, comprising: playing interval ( $\mathrm{min})$, total distance covered $(\mathrm{m})$, relative distance covered $\left(\mathrm{m} \cdot \mathrm{min}^{-1}\right)$, and both total and relative distance within six different speed categories (zones 1 to 6). Speed categories were individualized to each player based upon annually updated recordings of mean sprinting speed, measured with the same $5 \mathrm{~Hz}$ GPS device, over $30 \mathrm{~m}$ (zone 6; see Waldron, Worsfold, Twist \& Lamb, 2011b). Running speed associated with the final stage of the 20 m multi-stage fitness test (maximal aerobic velocity) was used to categorize zone 5. Zones 4, 3, 2 and 1 were calculated as; $75-100 \%, 50-75 \%, 25-50 \%, 0-25 \%$ of maximal aerobic velocity, respectively. Distance in zones 4 and above were regarded, and hereafter referred to, as highintensity. This category represents movement intensities within and above the highest quartile of maximal aerobic velocity. The mean maximal aerobic velocity and maximal sprinting speeds within each year group are presented in Table 2. 
*************************Table 2 near here $* * * * * * * * * * * * * * * * * * * * *$

Previous analyses have yielded 'moderate' to 'good' reliability (3\% to 9\% Coefficient of Variation; CV\%) using a similar demarcation of zones (Petersen, Pyne, Portus \& Dawson, 2009), which is sufficient to tolerate threats to reliability. Further outcome variables included: frequency of sprints (n), mean sprint distance (m), sprints per minute (sprints $\cdot \mathrm{min}^{-1}$ ), peak sprint distance $(\mathrm{m})$ and peak sprint speed $\left(\mathrm{km} \cdot \mathrm{h}^{-1}\right)$. The test-retest reliability $\mathrm{CV} \%$ has been shown to range from $1.84-2.06 \%$ and $1.92-2.06 \%$ for GPS measurements of distance and speed during maximal sprinting, respectively (Waldron et al., 2011b).

\section{Heart rates and ratings of perceived exertion}

A heart rate monitor (Polar Electro, Oy, Finland) was attached around the chest of the player, remaining in contact with the skin and secured using adhesive tape (Hypafix, Smith \& Nephew, US). Peak heart rate values were obtained prior to data collection using the multistage fitness test (Leger \& Lambert, 1982). Heart rates $\left(\mathrm{b} \cdot \mathrm{min}^{-1}\right)$ were recorded during match time and were later calculated as a percentage of each player's pre-determined peak heart rate. Summated heart rate was calculated based upon the method of Edwards (1993).

Twenty minutes post-match, players were asked to provide a global rating of perceived exertion for the match using a 0 - 10 scale, where 0 equated to rest and 10 to maximal (Foster et al., 2001). The rating of perceived exertion selected by each player was later multiplied by the number of minutes played to compute the so-called 'session-rating of perceived exertion'. 
The session-rating of perceived exertion is reported to be reliable over various exercise intensities, showing no systematic bias between repeated trials (Herman, Foster, Maher, Mikat \& Porcari, 2006).

\section{Assessment of maturity}

The age at peak height velocity required the assessment of stature, body mass, seated stature and leg length that were substituted into the equation of Mirwald, Baxter-Jones, Bailey and Beunen (2002). The maturity offset values were later subtracted from the chronological age of the players to calculate age at peak height velocity. Stature and seated stature were assessed using a stadiometer (Harpenden, Crymych, UK) recorded to the nearest mm, with a CV\% of $0.36 \%$ and $0.43 \%$ respectively. The CV\% was reported owing to heteroscedasticity in the data (Nevill \& Atkinson, 1997). Leg length was derived from the subtraction of seated stature form overall stature. Body mass was measured using Seca beam scales (Seca, Hamburg, Germany) to the nearest $0.1 \mathrm{~kg}$, with players wearing only the standard squad shorts and socks (the kit being worn was weighed and subsequently deducted from the final result).The age at peak height velocity for the selected groups in the under-15, -16 and $-17 \mathrm{~s}$ was $14.1 \pm 0.3 \mathrm{y}, 14.5 \pm 0.3 \mathrm{y}$ and $14.7 \pm 0.4 \mathrm{y}$, respectively. The age at peak height velocity for the selected groups in the under-15, -16 and $-17 \mathrm{~s}$ are presented in Table 2.

\section{Performance analysis}

For all matches, a camera (Canon MV 700i, $50 \mathrm{~Hz}$, Japan) was fixed to a tripod (Velbon, DV7000, Japan) and positioned in a gantry at a height of approximately $15 \mathrm{~m}$ perpendicular to the half-way line. The footage of each match was downloaded to a computer and imported 
to a manually operated behavioural recognition system (Dartfish TeamPro, 4.0.9.0, Switzerland), which was used to analyse successful and unsuccessful carries and tackles. Carries and tackles were included since they are key game skills that are performed by each player during matches. Tackling frequency has been analysed previously among adult rugby league players (Twist, Waldron, Highton, Burt \& Daniels, 2012), which is higher among elite compared to semi-elite players (Sirotic, Knowles, Coutts \& Catterick, 2009)

\begin{abstract}
All variables were expressed relative to the amount of playing time in order to normalize the data for each player. The intra-observer reliability of the selected match variables was assessed using the method of Cooper, Hughes, O'Donoghue \& Nevill (2007) and is presented in Table 3. A randomly selected 60-minute match from the study was coded for the above performance indicators on two different occasions, separated by two weeks. The frequency data from each trial were later separated into 40 equal chronological time segments (i.e. the first $1.5 \mathrm{~min}$ through to the final $1.5 \mathrm{~min}$ ) and aligned for analysis. Each performance indicator was evaluated for systematic bias using a median-sign test to compare the data of trials 1 and 2. Random variation was evaluated based upon the proportion (\%) of perfect agreement. These practical reference values represent the smallest possible error and were deemed appropriate given the experience of the analyst (six years in performance analysis) and familiarity with the sport and players involved.
\end{abstract}

*******************Table 3 near here $* * * * * * * * * * * * * * * * * *$ 
The intra-observer reliability tests showed no systematic bias between trials 1 and 2, 100\% perfect agreement for successful and unsuccessful tackles, and 91.9\% and 94.5\% agreement for successful and unsuccessful carries.

\section{Statistical analyses}

The mean match performances of players that were either selected or unselected at the conclusion of each age group were compared using independent $t$-tests (normally distributed data) or Mann-Whitney-U tests (non-normally distributed data). A secondary analysis of the same data was performed using a one-way analysis of co-variance with age at peak height velocity age at peak height velocity as a covariate (one-way ANCOVA). Normally distributed data, identified using the Shapiro-Wilk statistic $(P>0.05)$, were expressed as means and standard deviations (SD), whereas non-normal data were expressed as medians and inter-quartile ranges (IQR) throughout (Field, 2009). The distribution of the data determined the type of statistical test (i.e. parametric or non-parametric) to be used and, therefore, the way in which the data were expressed. Effect sizes (ES) were calculated as the difference between the means divided by the pooled standard deviation and presented with the associated 95\% Confidence Intervals (CI). For non-parametric data, the ES was calculated as the Z-score divided by the number of total observations (Field, 2009). Effect sizes were classified as: trivial $<0.2$, small $=0.21-0.6$, moderate $=0.61-1.2$, large $=1.21-1.99$, and very large >2.0 (Batterham \& Hopkins, 2006).

\section{Results}

Comparison of selected and unselected players by age group 
Independent $t$-tests showed no differences $(P>0.05)$ between the selected and unselected players among the under-15 or the under-17 age groups for any of the movement or physiological variables measured during match time. In the under-16 group, the selected players $(57.1 \pm 11.9 \mathrm{~min})$ had more available match time than the unselected $(44.1 \pm 12.3$ $\min )$ players $\left(t_{(21)}=2.580, P=0.017 ; \mathrm{ES}=1.08 \pm \mathrm{CI}=0.87\right)$. Accordingly, selected players covered more total distance $(5,181.0 \pm 1,063.5 \mathrm{~m} c f .3,942.6 \pm 1,108.6 \mathrm{~m}$, respectively; $P=$ $0.012 ; \mathrm{ES}=1.14 \pm \mathrm{CI}=0.88)$ than unselected players, as well as in zone $1(572.4 \pm 163.3 \mathrm{~m}$ cf. $434.3 \pm 135.0 \mathrm{~m}$, respectively; $P=0.039 ; \mathrm{ES}=0.92 \pm \mathrm{CI}=0.86)$, zone $3(572.4 \pm 163.3 \mathrm{~m}$ cf. $434.3 \pm 135.0 \mathrm{~m}$, respectively; $P=0.039 ; \mathrm{ES}=1.08 \pm \mathrm{CI}=0.87)$ and zone $4(913.4 \pm$ $188.8 \mathrm{~m} c f .686 .5 \pm 205.2 \mathrm{~m}$, respectively; $P=0.012 ; \mathrm{ES}=1.15 \pm \mathrm{CI}=0.85)$. Other timerelated variables such as summated-heart rate $(213.6 \pm 55.4 c f .156 .9 \pm 74.0$, respectively; $P$ $=0.049 ; \mathrm{ES}=0.97 \pm \mathrm{CI}=0.82)$, high-intensity distance $(1808.8 \pm 369.3 \mathrm{~m} c f .1380 .5 \pm 367.7$ $\mathrm{m}$, respectively; $P=0.011 ; \mathrm{ES}=1.16 \pm \mathrm{CI}=0.88)$ and session-rating of perceived exertion $(433.2 \pm 93.2$ cf. $313.4 \pm 81.2$, respectively; $P=0.004 ; \mathrm{ES}=1.37 \pm \mathrm{CI}=0.90)$, were higher for selected players compared to unselected players (Tables 4, $5 \& 6$ ). When age at peak height velocity was introduced as a covariate, only distance in zone 3 and summated-heart rate remained higher $(P<0.05)$ in the selected players of the under-16 age group. However, the ANCOVAs (using age at peak height velocity as the covariate), revealed higher values ( $P$ $<0.05$ ) amongst the unselected players for total and relative distances in zone 4, 5 and highintensity.

$* * * * * * * * * * * * * * * * * * * * * * *$ Tables 4, 5 \& 6 near here $* * * * * * * * * * * * * * * * * * * * * * *$ 
The Mann-Whitney-U tests revealed that selected players performed more successful carries $($ median $=6 ; \mathrm{IQR}=5$ to $8 c f$. median $=2 ; \mathrm{IQR}=1$ to $3, P<0.001 ; \mathrm{ES}=2.00 \pm \mathrm{CI}=1.02)$ and successful carries $\cdot \min ^{-1}$ (median $=0.127 ; \mathrm{IQR}=0.093$ to $0.168 c f$. median $=0.040 ; \mathrm{IQR}$ $=0.265$ to $0.845, P<0.001 ; \mathrm{ES}=0.22 \pm \mathrm{CI}=0.88)$ of the ball compared to unselected players in the under-15 group. No other differences $(P>0.05)$ between selected and unselected players in technical match actions were apparent for any other age group (Table 7).

$* * * * * * * * * * * * * * * * * * * * * * * * * * * * *$ Table 7 near here ${ }^{*} * * * * * * * * * * * * * * * * * * * * * * * * * * * *$

\section{Discussion}

The aim of the current study was to identify differences between selected and unselected players based on their average performances during match play. Unexpectedly, none of the match-related performance variables differentiated between these groups in both the under-15 and the under-17 age groups. However, within the under-16 age group, the selected players performed for longer average match periods compared to unselected players. Given that each of the selected and unselected groups were equally represented by either 'interchange' (two bouts or more) or full-match (single bout) players, there is no clear reason why additional playing minutes were offered to selected players. Fundamentally, selected players in the under-16 group were offered greater match exposure, which is considered to underpin the accumulation of real-world, competitive experience in higher ability athletes (Baker, 2003).

As a consequence of this selection bias, other time-related factors, such as total distance, high-intensity distance, Zones 1, 3 and 4 distances, session-rating of perceived exertion and summated heart rate were also higher in selected players of the under-16 group. For example, the session-rating of perceived exertion (433 AU) and summated-heart rate (213 AU) of the selected under-16 players was markedly higher than the unselected players (313 and $156 \mathrm{AU}$, 
respectively). These values are similar to those reported among adult players in the Super League (Waldron et al. 2011a) and semi-professional Australian rugby league players (Gabbett, 2004). Such findings were unanticipated, given the shorter duration of youth matches $(50-70 \mathrm{~min})$. As such, these are the first data to suggest that youth rugby league players globally perceive matches to be of a relatively higher intensity (rating of perceived exertion $=6.3-7.6)$ compared to adult players $(3.5-6.0$; Gabbett, 2004). While the reasons for such findings are presently unclear, it is assumed that the relative inexperience and reduced exposure to competitive match play accounts for the higher perceptual responses. The higher physiological load (session-rating of perceived exertion and summated-heart rate) of selected players of the under-16 group might also provide an additional match-like physiological stimulus enabling adaptation to the specific metabolic and mechanical demands of rugby league match play.

There were no measures of technical performance that were higher in selected players, aside from total and relative successful carries among the under-15 age group. In contrast, Gabbett, Jenkins and Abernethy (2010) showed that skills, performed in a simulated environment, were superior among elite compared to sub-elite players. However, the reliability of the techniques used by these authors has since been questioned (Waldron, Worsfold, Twist \& Lamb, 2012), and were unlikely to have provided valid simulations of the skills performed in matches. In an attempt to select the technical skills performed by players across positional groups, our analyses were restricted to tackling and carrying performance. Consequently, there were a variety of technical factors that were neglected in the current study, such as passing and kicking. This is a limitation of the current study's sample size (single squads) and might partly account for the lack of differences found between groups. However, it should be noted that selected and unselected groups comprised an even distribution of players from 
different positional roles at each age group. Furthermore, data that were excluded from the current study demonstrated that many players from certain positions (full-backs, wingers, centres, props) scarcely pass the ball across an entire season. Such findings provide important evidence of the limited exposure of youth rugby league players to traditional 'key' match skills. However, given the logical inclusion of skill-based assessments in talent identification research, future studies should consider extending analyses of technical skills to larger samples of youth rugby league players.

The assessment of performance variables, expressed relative to match time (i.e. $\mathrm{m} \cdot \mathrm{min}^{-1}$ ), demonstrated no difference between the selected and unselected groups, suggesting that the intensity (as opposed to duration) of match-running does not differentiate between selected or unselected players at any age group. Such findings are noteworthy since the playing interval represents the only measured variable that can be controlled by the coaches at the club, who are responsible for selecting players at the end of each season. It is unclear why such findings occur in the under-16 group, but it could be that additional pressure to win competitive matches or to offer 'favoured' players competitive match experience before progressing to academy level exists at this stage. Consequently, the markers of match performance measured herein have limited relevance for the identification of young rugby league players when data are normalized to individual match exposure.

When age at peak height velocity was introduced as a covariate in the analysis, unselected players in the under-16 group covered more total and relative distances in zone 4, 5 and highintensity. Therefore, the maturity of players moderates the relationship between selection status and match-running performance variables. This results in the likely de-selection of 
players who are performing more total and relative high-intensity running. While highintensity running is regarded as an important determinant of adult rugby league performance (Sirotic et al., 2009; Sykes et al., 2011), this is not reflected at younger age groups. Indeed, superior running performance appears to be rewarded with de-selection and is not a prerequisite of success during adolescence periods. The 'compensation phenomenon' may be considered as an explanation for such results, whereby team sports players of an inferior maturational status are thought to manufacture ways in which to stand-out above their selected peers (Williams \& Ericsson, 2005). Indeed, such a concept has been discussed as a potential problem for talent identification, since players that are selected on the basis of their performance in one dimension of talent might be overlooked in another (Vaeyens, Lenoir, Williams \& Philippaerts, 2008). In the current study, it is possible that the least mature, unselected players account for their physical insufficiencies by completing more high intensity running, yet this is unrecognised by the selectors. Therefore, our findings are inconsistent with the hypotheses of various qualitative studies in team sports, such as soccer, where it has been suggested that match-running performance partly explains the selection of players (Christensen, 2009; Vrljic \& Mallet, 2008). In contrast, our findings demonstrate that match-running performance does not underpin the coaches' selection of youth rugby league players.

High-intensity match running has been used to differentiate between rugby league players of an amateur or elite standard (Sirotic et al., 2009). Accordingly, it was anticipated that Highintensity running would distinguish between players of differing abilities. To meet the average match-running requirements of elite adult players, High-intensity running would need to increase by approximately $20 \%$ from the under-17 age group (Waldron et al., 2011a). Based on recent findings, the lower high-intensity running distance observed during matches 
compared to adults might be the consequence of an altered 'pacing' strategy among younger players (see Waldron, Highton, Daniels \& Twist, 2013). In this instance, the physically inferior, and less experienced, junior players are likely to down-regulate their exercise intensity in order to complete the bout (match). The relatively inferior predicted $\dot{\mathrm{V}} \mathrm{O}_{2 \max }$ of the current youth players $\left(52.7 \mathrm{ml} \cdot \mathrm{kg}^{-1} \cdot \mathrm{min}^{-1}\right)$ compared to that previously reported among elite adult players $\left(55.9 \mathrm{ml} \cdot \mathrm{kg}^{-1} \cdot \mathrm{min}^{-1}\right.$; Gabbett, Jenkins \& Abernethy, 2011a) might explain such findings. That is, developments in aerobic power during early adulthood might support the progression to the elite level. While other facets of performance, such as repeated-sprint ability, have moderate relationships to minutes played during rugby league matches $(r=0.3$; Gabbett, Jenkins \& Abernethy, 2011b), the same authors have demonstrated that this does not differentiate between higher (starters) and lower (non-starters or unselected) ability players (Gabbett, et al., 2011a). Furthermore, repeated-sprints performed during matches are often disregarded as a useful indicator of performance in rugby league, failing to differentiate between positional groups (Gabbett, 2012). However, among the same players, Gabbett et al. (2011a) found that $\dot{V} \mathrm{O}_{2 \max }$ was significantly higher among the starters and non-starters (55.7$\left.55.9 \mathrm{ml} \cdot \mathrm{kg}^{-1} \cdot \mathrm{min}^{-1}\right)$ compared to the unselected players $\left(53.2 \mathrm{ml} \cdot \mathrm{kg}^{-1} \cdot \mathrm{min}^{-1}\right)$, which is of a similar magnitude to that of the present study. Future studies should aim to find which facets of performance explain the improvements in high-intensity running during the transition from youth to adult match play.

\section{Conclusion}

This is the first study to report that match-related performance characteristics do not differentiate between elite youth rugby league players who are either selected or unselected by coaches at the end of each season. Rugby league practitioners should be aware of that the 
selection of players based on the match performance variables assessed herein, are unlikely to facilitate identification of higher-ability players. The only exception to such findings appears as a consequence of selected players being given a higher average time on the field of play during the under-16 season, resulting in increased total running distances, high-intensity running and the performance of game-related skills. When the results were expressed relative to match time, such differences were not apparent. Indeed, under statistical control for maturity, the unselected under-16 players were actually shown to perform more highintensity running, which is typically a marker of elite status among adult rugby league players (Sirotic et al., 2009). Therefore, those concerned with the selection of youth rugby league players should consider the influence of preferential selection on playing performance. Future research should explore alternative match-related performance measurements among young rugby players, since the variables measured herein do not characterise selection. In identifying the similarities of relative match performance among selected and unselected players, the current findings make a significant contribution to the search for abilities underlying talented performance in youth rugby league. 


\section{References}

Ali, A. (2011). Measuring soccer skill performance: a review. Scandinavian Journal of Science and Medicine in Sports, 21, 170-183.

Baker, J. (2003). Early specialization in youth sport: A requirement for adult expertise? High Ability Studies, 14, 85-94.

Batterham, A. M. \& Hopkins, W. G. (2006). Making meaningful inferences about magnitudes. International Journal of Sports Physiology and Performance, 1(1), 50-57.

Christensen, M. K. (2009). “An Eye for Talent”: Talent identification and the "Practical Sense" of top-level soccer coaches. Sociology of Sport Journal, 26, 365-382.

Cooper, S. M., Hughes, M., O'Donoghue, P., \& Nevill, A. M. (2007). A simple statistical method for assessing the reliability of data entered into sport performance analysis systems. International Journal of Performance Analysis in Sport, 7, 87-109.

Edwards S. (1993). The heart rate monitor book. Sacramento, CA: Fleet Feet Press.

Elferink-Gemser, M., T, Visscher, C., Lemmink, K. P. M., \& Mulder, T. W. (2004). Relation between multidimensional performance characteristics and level of performance in talented youth field hockey players. Journal of Sports Sciences, 22(11), 1053-1063.

Falk, B., Lidor, R., Lander, Y., \& Lang, B. (2004). Talent identification and early development of elite water-polo players: a 2-year follow-up study. Journal of Sports Sciences, 22(4), 347-355.

Field, A. (2009). Discovering Statistics using SPSS. London: SAGE. 
Foster, C., Florhaug, J. A, Franklin, J., Gottschall, L., Hrovatin, L. A, Parker, S., Doleshal, P., et al. (2001). A new approach to monitoring exercise training. Journal of Strength and Conditioning Research, 15(1), 109-115.

Gabbett, T. J. (2004). Influence of training and match intensity on injuries in rugby league, Journal of Sports Sciences, 22(5), 409-417.

Gabbett, T. J. (2009). Physiological and anthropometric characteristics of starters and nonstarters in junior rugby league players, aged 13-17. Journal of Sports Medicine and Physical Fitness, 49, 233-239.

Gabbett, T. J. (2012). Sprinting patterns of National Rugby League competition. Journal of Strength \& Conditioning Research, 26(1),121-130.

Gabbett, T. J., Jenkins, D. G. \& Abernethy, B. (2012). Physical demands of professional rugby league training and competition using microtechnology. Journal of Science and Medicine in Sport, 15(1), 80-86.

Gabbett, T. J, Jenkins, D. G., \& Abernethy, B. (2011). Relative importance of physiological, anthropometric, and skill qualities to team selection in professional rugby league, Journal of Sports Sciences, 29(13), 1453-1461.

Gabbett, T. J, Jenkins, D. G., \& Abernethy, B. (2011b). Relationships between physiological, anthropometric, and skill qualities and playing performance in professional rugby league players. Journal of Sports Sciences, 29(15), 1655-1664

Gabbett, T. J., Jenkins, D. G., \& Abernethy, B. (2010). Physiological and anthropometric correlates of tackling ability in junior elite and subelite rugby league players. Journal of Strength \& Conditioning Research, 24, 2989-2995. 
Gabbett, T., Kelly, J., \& Pezet, T. (2008). A comparison of fitness and skill among playing positions in sub-elite rugby league players. Journal of Science and Medicine in Sport, $11(6), 585-592$.

Herman, L., Foster, C. Maher, M. A., Mikat, R. P., \& Porcari, J. P. (2006). Validity and reliability of the session RPE method for monitoring exercise training intensity. South African Journal of Sports Medicine, 18(1), 14-17.

Jennings, D., Cormack, R., Coutts, A., Boyd, L., \& Aughey, R. (2010). The validity and reliability of GPS units in team sport specific running patterns. International Journal of Sports Physiology and Performance, 10(2), 67-72.

Leger, L. \& Lambert, J., (1982). A maximal multistage 20-m shuttle run test to predict V02 max. European Journal of Applied Physiology, 49, 1-12.

McLellan, C. P., Lovell, D. I., \& Gass, G. C. (2011). Performance analysis of elite rugby league match play using global positioning systems. Journal of Strength and Conditioning Research, 25(6), 1703-1710.

McMillan, K., Helgerud, J., Grant, S. J., Newell, J., Wilson, J., Macdonald, R., \& Hoff, J. (2005). Lactate threshold responses to a season of professional British youth soccer. British Journal of Sports Medicine, 39(7), 432-436.

Mirwald, R. L., Baxter-Jones, A. D. G., Bailey, D. A, \& Beunen, G. P. (2002). An assessment of maturity from anthropometric measurements. Medicine and Science in Sports and Exercise, 34(4), 689-694. 
Nevill, A.M. \& Atkinson, G. (1997). Assessing agreement between measurements recorded on a ratio scale in sports medicine and sports science. British Journal of Sports Medicine 31, 314-318.

Petersen, C., Pyne, D., Portus, M., \& Dawson, B. (2009). Validity and reliability of GPS units to monitor cricket-specific movement patterns. International Journal of Sports Physiology and Performance, 4(3), 381-393.

Ramsbottom, R., Brewer, J., \& Williams, C. (1988). A progressive shuttle run test to estimate maximal oxygen uptake. British Journal of Sports Medicine, 22(4), 141-144.

Sirotic, A. C., Coutts, A. J., Knowles, H., \& Catterick, C. (2009). A comparison of match demands between elite and semi-elite rugby league competition. Journal of Sports Sciences, 27(3), 203-211.

Sykes, S., Twist, C. Hall, S. Nicholas, C. \& Lamb, K. (2009). Semi-automated time-motion analysis of senior elite rugby league, International Journal of Performance Analysis in Sport, 21(3) 47-59.

Till, K., Cobley, S., O’Hara, J., Brightmore, A., Cooke, C., \& Chapman, C. (2011). Using anthropometric and performance characteristics to predict selection in junior UK Rugby League players. Journal of Science and Medicine in Sport, 14(3), 264-269.

Twist, C., Waldron, M., Highton, J., Burt, D., \& Daniels, M. (2012). Neuromuscular, biochemical and perceptual post-match fatigue in professional rugby league forwards and backs. Journal of Sports Sciences, 30, 359-367.

Unnithan, V., White, J., Georgiou, A., Iga, J. \& Drust, B. (2012) Talent identification in youth soccer. Journal of Sports Sciences, 30(15), 1719-1726. 
Vaeyens, R., Güllich, A., Warr, C. R., \& Philippaerts, R. (2009). Talent identification and promotion programmes of Olympic athletes. Journal of Sports Sciences, 27(13), 13671380.

Vrljic, K. \& Mallet, C. J. (2008). Coaching knowledge in identifying football talent. International Journal of Coaching Science, 2(1), 63-81.

Waldron, M., \& Worsfold, P. (2010). Differences in the game-specific skills of elite and subelite youth football players: implications for talent identification. International Journal of Performance Analysis in Sport, 10(1), 9-24.

Waldron, M., Twist, C., Highton, J., Worsfold, P., \& Daniels, M. (2011a). Movement and physiological match demands of elite rugby league using portable global positioning systems. Journal of Sports Sciences, 29(11), 1223-1230.

Waldron, M., Worsfold, P., Twist, C. \& Lamb, K. (2011b). Concurrent validity and test retest reliability of a Global Positioning System (GPS) and timing gates to assess sprint performance variables. Journal of Sports Sciences, 29, 1613-1619.

Waldron, M., Worsfold, P., Twist, C., \& Lamb, K. (2012). The reliability of tests for sportspecific skill amongst elite youth rugby league players. European Journal of Sports Science. Published ahead of print, DOI:10.1080/17461391.2012.714405.

Waldron, M., Highton, J., Daniels, M., \& Twist, C. (2013). Preliminary evidence of transient fatigue and pacing during interchanges in rugby league. International Journal of Sports Physiology and Performance, 8(2), 157-64 
Williams, A. M, \& Ericsson, K. A. (2005). Perceptual-cognitive expertise in sport: some considerations when applying the expert performance approach. Human Movement Science, 24(3), 283-307.

Witte, T. H., \& Wilson, A. M. (2004). Accuracy of non-differential GPS for the determination of speed over ground. Journal of Biomechanics, 37(12), 1891-1898. 

(1) 10 
Table 1. Sample sizes $(n)$ and descriptive of the selected and unselected players at the end of each year group

\begin{tabular}{|c|c|c|c|c|c|c|}
\hline & \multicolumn{2}{|c|}{ Under-15 group } & \multicolumn{2}{|c|}{ Under-16 group } & \multicolumn{2}{|c|}{ Under-17 group } \\
\hline & Selected & Unselected & Selected & Unselected & Selected & Unselected \\
\hline & $n=16$ & $n=5$ & $n=13$ & $n=8$ & $n=9$ & $n=6$ \\
\hline Age (y) & $15.1 \pm 0.3$ & $15.0 \pm 0.4$ & $16.3 \pm 0.3$ & $16.2 \pm 0.4$ & $17.0 \pm 0.3$ & $17.0 \pm 0.3$ \\
\hline Body mass (kg) & $83.3 \pm 8.9$ & $75.1 \pm 8.1$ & $83.2 \pm 8.3$ & $78.2 \pm 9.1$ & $88.7 \pm 9.7$ & $82.8 \pm 8.9$ \\
\hline Stature $(\mathrm{cm})$ & $180.2 \pm 4.4$ & $177.4 \pm 2.1$ & $179.8 \pm 4.3$ & $178.2 \pm 2.4$ & $180.1 \pm 4.3$ & $181.1 \pm 4.7$ \\
\hline$\dot{\mathrm{V}} \mathrm{O}_{2 \max }\left(\mathrm{ml} \cdot \mathrm{kg}^{-1} \cdot \mathrm{min}^{-1}\right)$ & $48.1 \pm 3.4$ & $47.4 \pm 5.7$ & $49.2 \pm 3.6$ & $46.6 \pm 4.7$ & $52.7 \pm 3.8$ & $52.3 \pm 3.2$ \\
\hline
\end{tabular}

Note: $\dot{V} O_{2 \max }\left(\mathrm{ml} \mathrm{kg}^{-1} \cdot \mathrm{min}^{-1}\right)$ is based on predicted values from the $20 \mathrm{~m}$ multi-stage fitness test (Ramsbottom, Brewer \& Williams, 1988).

Table 2. The mean \pm SD speeds $\left(\mathrm{km} \cdot \mathrm{h}^{-1}\right)$ used to individualize zones 5 and 6 and the APHV of adolescent rugby league players

\begin{tabular}{|c|c|c|c|}
\hline \multirow[b]{2}{*}{ Zone } & \multicolumn{3}{|c|}{ Age group } \\
\hline & Under-15 & Under-16 & Under-17 \\
\hline Zone $5-$ max aerobic speed $\left(\mathrm{km} \cdot \mathrm{h}^{-1}\right)$ & $13.9 \pm 0.7$ & $13.9 \pm 0.6$ & $14.3 \pm 0.7$ \\
\hline Zone 6 - Sprinting speed $\left(\mathrm{km} \cdot \mathrm{h}^{-1}\right)$ & $21.1 \pm 1.2$ & $21.5 \pm 1.0$ & $22.2 \pm 0.9$ \\
\hline Age at Peak height velocity $(y)$ & $14.5 \pm 0.5$ & $14.9 \pm 0.7$ & $14.9 \pm 0.4$ \\
\hline
\end{tabular}


Table 3. Intra-observer reliability of selected performance indicators

\begin{tabular}{cccc}
\hline Indicator & Median-Sign Test $(\boldsymbol{P}$-value $)$ & PA $=\mathbf{0}(\boldsymbol{\%})$ & $\mathbf{9 5 \%}$ Confidence Interval $(\boldsymbol{\%})$ \\
\hline Su carry & 1.000 & 91.9 & 78.9 to 100 \\
Un carry & 0.500 & 94.5 & 83.8 to 100 \\
Su tackle & 1.000 & 100 & 100 to 100 \\
Un tackle & 1.000 & 100 & 100 to 100 \\
\hline
\end{tabular}

Note: Su = successful; Un = unsuccessful; $P A=$ perfect agreement. 
Table 4. Comparison of selected and unselected players by age group (under-15 to under-17) for playing interval (min), total distance (m) and both total and relative $\left(\mathrm{m} \cdot \mathrm{min}^{-1}\right)$ distance covered in six speed zones.

\begin{tabular}{|c|c|c|c|c|c|c|c|c|c|c|c|c|c|c|c|c|}
\hline \multirow[b]{3}{*}{ Interval (min) } & \multicolumn{4}{|c|}{ Under-15 group } & \multicolumn{6}{|c|}{ Under-16 group } & \multicolumn{6}{|c|}{ Under-17 group } \\
\hline & \multicolumn{2}{|c|}{ Selected $(n=16)$} & \multicolumn{2}{|c|}{ Unselected $(n=6)$} & \multicolumn{3}{|c|}{ Selected $(n=13)$} & \multicolumn{3}{|c|}{ Unselected $(n=8)$} & \multicolumn{3}{|c|}{ Selected $(n=9)$} & \multicolumn{3}{|c|}{ Unselected $(n=6)$} \\
\hline & $49.8^{\mathrm{S}}$ & \pm 10.8 & 53.8 & \pm 12.1 & $57.2 *^{\mathrm{M}}$ & \pm & 12.0 & 44.1 & \pm & 12.3 & $73.0^{\mathrm{M}}$ & \pm & 14.7 & 55.4 & \pm & 23.0 \\
\hline Total distance $(m)$ & $4,112.9^{\mathrm{S}}$ & \pm 888.6 & $4,478.8$ & \pm 898.2 & $5,181.0 * \mathrm{M}$ & \pm & $1,063.5$ & $3,942.6$ & \pm & $1,108.6$ & $6,392.4^{\mathrm{M}}$ & \pm & $1,238.7$ & $4,962.0$ & \pm & $1,958.9$ \\
\hline Total $\mathrm{m} \cdot \mathrm{min}^{-1}$ & $81.2^{\mathrm{S}}$ & \pm 5.7 & 84.4 & \pm 5.8 & $90.8^{\mathrm{S}}$ & \pm & 5.0 & 88.7 & \pm & 4.5 & $88.0^{\mathrm{M}}$ & \pm & 3.8 & 90.9 & \pm & 3.4 \\
\hline Distance in Zone $1(\mathrm{~m})$ & $492.2^{\mathrm{S}}$ & \pm 122.8 & 528.2 & \pm 162.6 & $572.4 *^{\mathrm{M}}$ & \pm & 163.3 & 434.3 & \pm & 135.0 & $748.0^{\mathrm{M}}$ & \pm & 218.0 & 550.3 & \pm & 250.7 \\
\hline Distance in Zone $2(\mathrm{~m})$ & $1,469.2^{\mathrm{T}}$ & \pm 443.8 & $1,495.6$ & \pm 638.7 & $1,788.2^{\mathrm{M}}$ & \pm & 485.5 & $1,369.1$ & \pm & 526.3 & $2,262.1^{\mathrm{M}}$ & \pm & 584.6 & $1,666.1$ & \pm & 828.4 \\
\hline Distance in Zone 3 (m) & $839.6^{\mathrm{S}}$ & \pm 252.7 & 915.4 & \pm 295.0 & $1,022.0 * \dagger^{\mathrm{M}}$ & \pm & 256.5 & 759.8 & \pm & 229.1 & $1,267.3^{\mathrm{M}}$ & \pm & 297.2 & 995.9 & \pm & 329.4 \\
\hline Distance in Zone $4(\mathrm{~m})$ & $682.1^{\mathrm{M}}$ & \pm 144.3 & 820.8 & \pm 259.3 & $913.4 * \dagger^{\mathrm{M}}$ & \pm & 188.8 & 686.5 & \pm & 205.2 & $1,092.4^{\mathrm{M}}$ & \pm & 269.0 & 854.6 & \pm & 233.0 \\
\hline Distance in Zone 5 (m) & $493.8^{S}$ & \pm 191.4 & 600.3 & $\pm \quad 318.7$ & $711.0 \dagger^{\mathrm{S}}$ & \pm & 195.6 & 581.8 & \pm & 212.2 & $925.3^{\mathrm{S}}$ & \pm & 198.0 & 803.4 & \pm & 383.4 \\
\hline Distance in Zone $6(\mathrm{~m})$ & $131.3^{\mathrm{S}}$ & \pm 25.0 & 121.2 & \pm 48.6 & $184.4^{\mathrm{M}}$ & \pm & 104.4 & 112.2 & \pm & 64.7 & $97.8^{\mathrm{T}}$ & \pm & 52.3 & 91.5 & \pm & 39.3 \\
\hline $\mathrm{Z1} \mathrm{m} \cdot \mathrm{min}^{-1}$ & $9.6^{\mathrm{T}}$ & \pm 0.9 & 9.6 & \pm 1.3 & $9.9^{\mathrm{T}}$ & \pm & 1.2 & 9.9 & \pm & 1.2 & $10.1^{\mathrm{S}}$ & \pm & 1.5 & 9.7 & \pm & 0.9 \\
\hline $\mathrm{Z} 2 \mathrm{~m} \cdot \min ^{-1}$ & $27.9^{\mathrm{T}}$ & \pm 4.0 & 27.1 & \pm 6.1 & $30.9^{\mathrm{T}}$ & \pm & 3.1 & 30.4 & \pm & 4.9 & $30.8^{\mathrm{S}}$ & \pm & 3.2 & 29.2 & \pm & 3.7 \\
\hline $\mathrm{Z3} \mathrm{m} \cdot \mathrm{min}^{-1}$ & $16.8^{\mathrm{T}}$ & \pm 2.6 & 17.0 & \pm 2.8 & $18.1^{\mathrm{M}}$ & \pm & 3.6 & 17.1 & \pm & 3.7 & $17.4^{\mathrm{S}}$ & \pm & 2.6 & 18.5 & \pm & 3.3 \\
\hline $\mathrm{Z} 4 \mathrm{~m} \cdot \min ^{-1}$ & $14.4^{\mathrm{S}}$ & \pm 3.7 & 16.7 & \pm 7.7 & $18.5 \dagger^{\mathrm{T}}$ & \pm & 7.8 & 17.8 & \pm & 4.6 & $15.4^{\mathrm{S}}$ & \pm & 4.4 & 16.5 & \pm & 3.5 \\
\hline $\mathrm{Z5} \mathrm{m} \cdot \min ^{-1}$ & $9.6^{\mathrm{S}}$ & \pm 3.0 & 11.8 & \pm 6.2 & $12.6 \dagger^{S}$ & \pm & 2.6 & 13.2 & \pm & 3.2 & $12.8^{\mathrm{M}}$ & \pm & 1.7 & 14.5 & \pm & 2.9 \\
\hline $\mathrm{Z6} \mathrm{m} \cdot \mathrm{min}^{-1}$ & $2.8^{\mathrm{M}}$ & \pm 0.9 & 2.2 & \pm 0.6 & $3.2^{\mathrm{S}}$ & \pm & 1.5 & 2.6 & \pm & 1.3 & $1.4^{\mathrm{S}}$ & \pm & 0.8 & 1.8 & \pm & 0.9 \\
\hline
\end{tabular}

Note: $Z=$ zone $; *$ different $(<0.05)$ than comparative age group. $\dagger=$ different $(<0.05)$ than comparative age group under statistical control for maturational age. Adjusted means not presented. $T=$ trivial $(<0.2) ; S=\operatorname{small}(0.21-0.6) ; M=$ moderate $(0.61-1.2) ; L=$ large $(1.21-1.99)$. 
Table 5. Comparison of selected and unselected players by age group (under-15 to under-17) for total (m) and relative high intensity distance covered (high-intensity $\left.\cdot \mathrm{min}^{-1}\right)$, total $(\mathrm{n})$ and relative $\left(\mathrm{n} \cdot \mathrm{min}^{-1}\right)$ sprint frequency, mean sprint distance $(\mathrm{m})$ and peak sprint speed $\left(\mathrm{km} \cdot \mathrm{h}^{-1}\right)$ and distance (m).

\begin{tabular}{|c|c|c|c|c|c|c|c|c|c|c|c|c|}
\hline \multirow[b]{3}{*}{ High-intensity (m) } & \multicolumn{4}{|c|}{ Under-15 group } & \multicolumn{5}{|c|}{ Under-16 group } & \multicolumn{3}{|c|}{ Under-17 group } \\
\hline & \multicolumn{2}{|c|}{ Selected $(n=16)$} & \multicolumn{2}{|c|}{ Unselected $(n=6)$} & \multicolumn{2}{|c|}{ Selected $(n=13)$} & \multicolumn{3}{|c|}{ Unselected $(n=8)$} & \multicolumn{2}{|c|}{ Selected $(n=9)$} & Unselected $(n=6)$ \\
\hline & $1,307.2^{\mathrm{M}}$ & \pm 327.9 & $1,542.3$ & \pm 555.7 & $1,808.8 * \dagger^{\mathrm{M}}$ & \pm 369.3 & $1,380.5$ & \pm & 367.7 & $2,115.5^{\mathrm{M}}$ & \pm 373.5 & $1,749.5 \pm 610.0$ \\
\hline High-intensity $\cdot \min ^{-1}$ & $26.8^{\mathrm{S}}$ & \pm 6.5 & 30.7 & \pm 13.2 & $32.2 \dagger^{\mathrm{T}}$ & \pm 4.7 & 31.7 & \pm & 5.6 & $29.8^{\mathrm{M}}$ & \pm 5.4 & \pm 4.2 \\
\hline Sprints (n) & $13.2^{\mathrm{S}}$ & \pm 2.6 & 12.4 & \pm 5.3 & $17.0^{\mathrm{M}}$ & \pm 8.5 & 10.9 & \pm & 5.9 & $9.6^{\mathrm{T}}$ & \pm 3.9 & \pm 5.2 \\
\hline Sprints $\cdot \min ^{-1}$ & $0.3^{\mathrm{M}}$ & \pm 0.1 & 0.2 & \pm 0.1 & $0.3^{\mathrm{M}}$ & \pm 0.1 & 0.2 & \pm & 0.1 & $0.1^{\mathrm{M}}$ & \pm 0.1 & \pm 0.1 \\
\hline Mean sprint distance (m) & $10.5^{\mathrm{S}}$ & \pm 3.2 & 9.9 & \pm 2.6 & $10.8^{\mathrm{T}}$ & \pm 3.0 & 10.1 & \pm & 4.8 & $12.6^{\mathrm{M}}$ & \pm 6.8 & \pm 4.1 \\
\hline Peak sprint distance (m) & $35.9^{\mathrm{T}}$ & \pm 7.8 & 36.9 & \pm 9.3 & $38.4^{\mathrm{M}}$ & \pm 8.6 & 30.8 & \pm & 15.8 & $31.2^{\mathrm{S}}$ & \pm 11.7 & \pm 9.3 \\
\hline Peak speed $\left(\mathrm{km} \cdot \mathrm{h}^{-1}\right)$ & $27.0^{\mathrm{T}}$ & \pm 1.1 & 27.2 & \pm 1.5 & $28.2^{\mathrm{S}}$ & \pm 1.6 & 27.4 & \pm & 3.4 & $28.0^{\mathrm{S}}$ & \pm 2.0 & \pm 1.5 \\
\hline
\end{tabular}

Note: $*$ different $(<0.05)$ than comparative age group. $\dagger=$ different $(<0.05)$ than comparative age group under statistical control for maturational age. Adjusted means not presented. $T=$ trivial $(<0.2) ; S=\operatorname{small}(0.21-0.6) ; M=$ moderate $(0.61-1.2) ; L=$ large $(1.21-1.99)$. 
Table 6. Comparison of selected and unselected players by age group (under-15 to under-17) for percentage of heart rate peak, summated-heart rate and perceptual responses during match time.

\begin{tabular}{|c|c|c|c|c|c|c|c|c|c|c|c|c|}
\hline \multirow[b]{3}{*}{ Percentage heart rate peak } & \multicolumn{4}{|c|}{ Under-15 group } & \multicolumn{4}{|c|}{ Under-16 group } & \multicolumn{4}{|c|}{ Under-17 group } \\
\hline & \multicolumn{2}{|c|}{ Selected $(n=16)$} & \multicolumn{2}{|c|}{ Unselected $(n=6)$} & \multicolumn{2}{|c|}{ Selected $(n=13)$} & \multicolumn{2}{|c|}{ Unselected $(n=8)$} & \multicolumn{2}{|c|}{ Selected $(n=9)$} & \multicolumn{2}{|c|}{ Unselected $(n=6)$} \\
\hline & $78.8^{\mathrm{S}}$ & \pm 4.8 & 79.7 & \pm 3.7 & $83.0^{\mathrm{T}}$ & \pm 3.0 & 82.4 & \pm 5.0 & $82.1^{\mathrm{S}}$ & \pm 2.0 & 83.2 & \pm 3.3 \\
\hline Summated-heart rate (AU) & $178.0^{\mathrm{S}}$ & 47.4 & 194.8 & 51.6 & $213.6 * \dagger^{\mathrm{M}}$ & 55.4 & 156.9 & 74.0 & $266.2^{\mathrm{L}}$ & 38.3 & 202.8 & 64.6 \\
\hline Rating of perceived exertion & $6.9^{\mathrm{S}}$ & \pm 0.7 & 6.7 & 0.8 & $7.6^{\mathrm{S}}$ & 0.5 & 7.2 & 0.9 & $6.8^{\mathrm{M}}$ & 0.9 & 6.3 & 0.7 \\
\hline Session rating of perceived exertion $(A U)$ & $353.8^{\mathrm{T}}$ & \pm 98.7 & 358.8 & 99.7 & $433.2 * \mathrm{~L}$ & 93.2 & 313.4 & 81.2 & $498.9^{\mathrm{M}}$ & 117.3 & 353.5 & 165.8 \\
\hline
\end{tabular}


Table 7. Comparisons between selected and unselected players by age group (under-15 to under-17) for selected technical actions

\begin{tabular}{lcccccc}
\hline & \multicolumn{2}{c}{ Under-15 group } & \multicolumn{2}{c}{ Under-16 group } & \multicolumn{2}{c}{ Under-17 group } \\
\hline & $\begin{array}{c}\text { Selected } \\
(n=16)\end{array}$ & $\begin{array}{c}\text { Unselected } \\
(n=6)\end{array}$ & $\begin{array}{c}\text { Selected } \\
(n=13)\end{array}$ & $\begin{array}{c}\text { Unselected } \\
(n=8)\end{array}$ & $\begin{array}{c}\text { Selected } \\
(n=9)\end{array}$ & $\begin{array}{c}\text { Unselected } \\
(n=6)\end{array}$ \\
\hline Successful carry & $6^{* \mathrm{VL}}$ & 2 & $7^{\mathrm{T}}$ & 7 & $9^{\mathrm{M}}$ & 5 \\
Unsuccessful carry & $1^{\mathrm{T}}$ & 1 & $1^{\mathrm{T}}$ & 1 & $3^{\mathrm{M}}$ & 1 \\
Successful tackle & $11^{\mathrm{S}}$ & 10 & $12^{\mathrm{S}}$ & 13 & $13^{\mathrm{M}}$ & 8 \\
Unsuccessful tackle & $2^{\mathrm{S}}$ & 1 & $2^{\mathrm{T}}$ & 2 & $5^{\mathrm{S}}$ & 1 \\
Successful carry $\cdot$ min $^{-1}$ & $0.13^{* \mathrm{~S}}$ & 0.04 & $0.10^{\mathrm{T}}$ & 0.13 & $0.17^{\mathrm{T}}$ & 0.13 \\
Unsuccessful carry $\cdot \boldsymbol{m i n}^{-1}$ & $0.01^{\mathrm{T}}$ & 0.01 & $0.02^{\mathrm{T}}$ & 0.01 & $0.30^{\mathrm{T}}$ & 0.03 \\
Successful tackle $\cdot$ min $^{-1}$ & $0.23^{\mathrm{T}}$ & 0.16 & $0.21^{\mathrm{T}}$ & 0.24 & $0.16^{\mathrm{T}}$ & 0.33 \\
Unsuccessful tackle $\cdot \boldsymbol{m i n}^{-1}$ & $0.02^{\mathrm{T}}$ & 0.02 & $0.04^{\mathrm{T}}$ & 0.04 & $0.08^{\mathrm{T}}$ & 0.07 \\
\hline Sit
\end{tabular}

Note: $*=$ different $(P<0.05)$ than comparative age group. $T=$ trivial $(<0.2) ; S=\operatorname{small}(0.21-0.6) ; M=$ moderate $(0.61$ 1.2); $L=$ large (1.21-1.99; $V L=$ very large $(>1.99)$. 